\title{
OUD Care Service Improvement with Prolonged-release Buprenorphine in Prisons: Cost Estimation Analysis
}

This article was published in the following Dove Press journal: ClinicoEconomics and Outcomes Research

\author{
Nat Wright ${ }^{\prime}$ \\ Jake Hard ${ }^{2}$ \\ Colin Fearns (iD ${ }^{3}$ \\ Mark Gilman iD ${ }^{4}$ \\ Richard Littlewood ${ }^{5}$ \\ Rachael Clegg ${ }^{6}$ \\ Luxman Parimelalagan (1D ${ }^{3}$ \\ Farrukh Alam ${ }^{7}$ \\ 'Spectrum Community Health $\mathrm{CIC}$, \\ Wakefield, UK; ${ }^{2}$ Royal College of General \\ Practitioners, London, UK; ${ }^{3}$ Delphi \\ Medical, Lancashire, UK; ${ }^{4}$ Discovering \\ Health, Manchester, UK; ${ }^{5}$ applied strategic, \\ London, UK; ${ }^{6}$ Change Grow Live, Brighton, \\ UK; ${ }^{7}$ Central \& North West London NHS \\ Foundation Trust, London, UK
}

Background: In prisons in England, integrated treatment for opioid use disorder (OUD) is accessible and effective, commonly based on daily supervised consumption of methadone. Treatment limitations (inadequate dosing, nonengagement with care, stigma, diversion and bullying) are noted. Flexible dose, injectable prolonged-release buprenorphine (PRB) which removes the need for daily dispensing and supervision is suggested for prisoner care. This work aimed to predict the difference in costs of current standard of care vs partial introduction of PRB.

Methods: A predictive model of compared costs for the provision of OUD care in the prison setting in England evaluated current standard of care (all receive methadone) with a future situation of $30 \%$ of prisoners electing to use a monthly dose of PRB. Evidence describing costs to deliver OUD care for 150 prisoners (pharmacotherapy, direct service, indirect health care, indirect security costs) were collected, including assumptions describing how care would be delivered. Evidence sources include national data sources, scientific literature and from experience in the prison health care setting.

Results: For a representative standard prison population requiring OUD care of 150 prisoners in England PRB introduction is associated with a predicted reduction in direct and indirect costs of OUD care. Annual OUD care costs for current standard of care were $£ 0.6 \mathrm{M}$; with $30 \%$ PRB costs reduced by $£ 8665$, more than 3000 hours of staff time is saved. Sensitivity analyses showed greater adoption of PRB resulted in further cost reduction.

Conclusion: PRB can address limitations of OUD care in prisons and improve outcomes. Introduction does not increase cost of care in this predictive analysis. PRB may lead the transformation of prisoner OUD care.

Keywords: opioid use disorder, pharmacotherapy, prolonged-release buprenorphine, prisoners

\section{Introduction}

There is an opportunity to improve opioid use disorder (OUD) care in prisons. OUD is associated with serious adverse health and social outcomes. ${ }^{1}$ People with OUD often face social disadvantage, may find it difficult to access appropriate health care services ${ }^{2}$ and are disproportionately represented in the criminal justice system, ${ }^{3-5}$ related to acquisitive crime and illegal substances possession. ${ }^{6}$ It is estimated that $60 \%$ have a history of problem drug use, 35\% may be engaged in OUD treatment programs in prisons. ${ }^{7}$ For many, prison-based health-care is an important opportunity to engage with services not accessed in the community. ${ }^{8}$
Correspondence: Nat Wright Spectrum Community Health CIC, One Navigation Walk, Hebble Wharf, Wakefield WFI 5RH, UK

Email natwright@nhs.net 
Pharmacotherapy, commonly methadone administered each day under supervision of custodial prison and healthcare staff, ${ }^{9}$ is the standard of care for prisoners in England $^{3,5,10}$ and is effective and well-evidenced. ${ }^{11-13}$ OUD care in prison is associated with limitations: attendance for observed therapy may increase the chance of bullying, harassment and exploitation ${ }^{3}$ and limit time for employment and rehabilitation. Diversion and misuse of medications is a recognized problem in the prison setting. ${ }^{3,14}$ The risk of diversion limits access to oral buprenorphine as a choice in therapy. ${ }^{3}$ Suboptimal dosing may occur in the prison setting ${ }^{15}$ and increases likelihood of engagement in "on top" use of opioids or other drugs obtained through illicit routes. On release many do not continue to engage with treatment services; ${ }^{16}$ there is an important risk of overdose following exposure to illicit heroin on release. ${ }^{17}$

Flexible dose, injectable prolonged-release buprenorphine (PRB), administered by injection with various doses providing a sustained therapeutic plasma concentration of buprenorphine over weekly or monthly dosing intervals, has been available in the UK since January $2019^{18}$ with demonstrated efficacy. ${ }^{19-21}$ PRB minimizes risk of diversion, removes the need for daily dispensing, limits stigma and bullying risk associated with oral observed therapy and may be a useful choice when clarity for counselling to address trauma is required. ${ }^{22}$ PRB has been recommended ${ }^{23,24}$ with potential benefits defined ${ }^{25}$ and studied, in the prison setting. ${ }^{26}$ The objective of this work was to compare estimated costs of providing the standard of care with PRB introduction.

\section{Method}

A predictive model to estimate the costs of OUD care in prison was prepared from the perspective of the health-care provider. The setting was the public prison system in England, in which health care is the responsibility of the National Health Service. Costs to deliver OUD care (pharmacotherapy, direct service, indirect health care or security) were calculated for a typical representative standard prisoner population. Costs were compared for the current standard of care (all treated prisoners receive methadone medication) and with a novel approach assuming 30\% elect for PRB therapy.

Direct costs for OUD care consisted of drug and staff costs. Drug costs: cost of methadone was calculated based on an average daily dose of $60 \mathrm{mg}$ per patient, the minimum therapeutic dose recognized in national guidelines ${ }^{5}$ and listed unit cost data. PRB drug cost was determined from the fixed cost for 30-day supply in England. ${ }^{19}$
To estimate staff costs related to the provision of observed methadone consumption in a prison, a process map of activities required for treatment delivery was created based on evidence from three prisons. Time to complete activities was determined (Table 1) and unit costs for staff time applied. Activities included: (1) Setup: preparation tasks before initiating the dispensing process. (2) Escort to treatment: transfer of prisoners between cells and dispensing location. (3) Dispensing: daily dispensing of medications at the designated location and supervision of this process. (4) Completion: "close down", tasks including cleaning the automated dispensing system and recording of final stock balance. (5) Administration: tasks to manage the procurement and daily supply within the prison of a controlled drug including medication orders, medication transport, script checks, spillage investigations.

For monthly PRB treatment a novel treatment process was assumed with pharmacotherapy administered during

Table I Direct Costs: Utilization Rates

\begin{tabular}{|c|c|c|c|}
\hline Cost Type & & Utilization & \\
\hline \multirow[t]{2}{*}{ Medication } & & Methadone & $\begin{array}{l}\text { Prolonged- } \\
\text { release } \\
\text { buprenorphine }\end{array}$ \\
\hline & & $\begin{array}{l}\text { Daily dose } \\
60 \mathrm{mg}\end{array}$ & $\begin{array}{l}\text { Monthly dose } \\
8,16,24 \text {, } \\
32 \mathrm{mg}\end{array}$ \\
\hline $\begin{array}{l}\text { Dispensing } \\
\text { system }\end{array}$ & & $1^{*}$ & $0^{* *}$ \\
\hline Staff & Process & $\begin{array}{l}\text { Resource } \\
\text { use }^{\#} \\
\text { (h/week) }\end{array}$ & \\
\hline Prison officer & $\begin{array}{l}\text { Escort offenders } \\
\text { Dispensing }\end{array}$ & $\begin{array}{l}63.0 \\
31.5\end{array}$ & $\begin{array}{l}0.0 \\
0.0\end{array}$ \\
\hline Nurse & $\begin{array}{l}\text { Setup } \\
\text { Dispensing } \\
\text { Completion }\end{array}$ & $\begin{array}{l}5.3 \\
31.5 \\
5.3\end{array}$ & $\begin{array}{l}0.0 \\
6.0 \\
0.0\end{array}$ \\
\hline $\begin{array}{l}\text { Pharmacy } \\
\text { technician }\end{array}$ & $\begin{array}{l}\text { Setup } \\
\text { Dispensing } \\
\text { Completion } \\
\text { Weekly administration }\end{array}$ & $\begin{array}{l}5.3 \\
31.5 \\
5.3 \\
16.5\end{array}$ & $\begin{array}{l}0.0 \\
3.0 \\
0.0 \\
3.0\end{array}$ \\
\hline Pharmacist & Weekly administration & 25.5 & 9.8 \\
\hline Prescriber & Weekly administration & 7.5 & 3.8 \\
\hline
\end{tabular}

Notes: *One Methasoft system set up for a prison with 150 people in treatment. **Does not require automatic dispensing system. " Describes weekly staff resource required to serve 150 patients in treatment. 
Table 2 Indirect Costs: Utilization Rates

\begin{tabular}{|l|l|l|l|}
\hline \multirow{2}{*}{ Cost Type } & \multicolumn{2}{|l|}{ Utilization (Events/Year) } & \multicolumn{2}{|l|}{ Reference } \\
\cline { 2 - 4 } & Methadone & $\begin{array}{l}\text { Prolonged-release } \\
\text { Buprenorphine }\end{array}$ & \\
\hline Indirect health care & & & 30 Assumption \\
Diversion-related medication review & 780.00 & 0.00 & $30,3 \mathrm{~b}$ \\
Overdose & 156.00 & 78.00 & $31,32 \mathrm{~b}$ \\
Ambulance call out for overdose & 0.86 & 0.47 & $31,33 \mathrm{~b}$ \\
Drug-related death (in custody) & 0.04 & 0.02 & $31,34 \mathrm{~b}$ \\
Drug-related death (post release) & 0.75 & 0.45 & $30,35 \mathrm{~b}$ \\
\hline Indirect security/criminal justice & & & $30,35 \mathrm{~b}$ \\
Adjudications for violence & 52.5 & 36.00 & 30 Assumption \\
Sentence day added for violence & 4.65 & 3.30 & $36,37 \mathrm{~b}$ \\
Adjudication for diversion attempt & 780.00 & 0.00 & $36,37 \mathrm{~b}$ \\
Arrest (post release) & 61.5 & 21.00 & 21.00 \\
Court appearance (post release) & 61.5 & & \\
\hline
\end{tabular}

Notes: ${ }^{\mathrm{a}}$ Number of occurrences annually per 150 patients in treatment ${ }^{\mathrm{b}}$ Model input values assumed based on extrapolation of referenced data.

a 10-minute nurse appointment during a preexisting health care appointment ${ }^{27}$ without daily supervision.

Events determining indirect health-care costs and indirect security or criminal justice costs relating to OUD in prisons were identified (Table 2) from typical practice in three prisons or other published evidence, with assumptions for related costs (Table 3). These included: medication reviews following attempted diversion, staff costs associated with an overdose incident, naloxone medication provision, emergency medical service or ambulance call outs, drug-related deaths during custody and in a one-year period following release.

Indirect security or criminal justice costs included: management time for investigation of, and arrests for violence related to, the diversion of OUD medication. This included adjudications or sentencing, punishment (including added sentence days).

A standard OUD treatment population of 150 prisoners was assessed for the purposes of the estimation. This was based on an average prison population of 700 , calculated from national statistics, ${ }^{28}$ and reported rates of uptake of OUD treatment. ${ }^{7}$

Current standard of care included 100\% methadone use, as is common in England. The comparison modelled a $30 \%$ adoption of monthly dose of PRB, in line with buprenorphine prescribing in community practice. $^{29}$

A sensitivity analysis was performed to assess the impact of key parameters which may be variable across prisons including medication dose, staff time, and new therapy adoption level on overall costs.

\section{Results}

Introduction of PRB for $30 \%$ of care is associated with a modelled cost reduction of $£ 8665$ (Table 4). Standard of care costs were $£ 292,420$ (direct service), $£ 96,632$

Table 3 Unitary Costs

\begin{tabular}{|c|c|c|}
\hline Cost Parameter & Unit Cost ( $(E)$ & Reference \\
\hline \multicolumn{3}{|l|}{ Medication } \\
\hline Methadone (I mg/mL, oral solution) & $0.54 / 60 \mathrm{mg}$ dose & 38 \\
\hline Prolonged-release buprenorphine & 239.70/30-day supply & 19 \\
\hline \multicolumn{3}{|l|}{ Logistics } \\
\hline Dispensing system fee & $200.00 /$ month & 39 \\
\hline \multicolumn{3}{|l|}{ Staff, hourly rate } \\
\hline Prison officer & 19.15 & 40 \\
\hline Nurse & 22.70 & 41 \\
\hline Pharmacy technician & 17.02 & 42 \\
\hline Pharmacist & 28.37 & 43 \\
\hline Prescriber & 67.38 & 44 \\
\hline \multicolumn{3}{|l|}{ Indirect healthcare } \\
\hline Medication review & 17.00 & 30,44 \\
\hline Overdose (staff resource) & 195.00 & $30,40,41$ \\
\hline Naloxone $(400 \mu \mathrm{g} / \mathrm{mL})$ & 8.16 & 38 \\
\hline Ambulance callout & 300.00 & 45 \\
\hline Drug-related death (in custody) & $60,000.00$ & 30 \\
\hline Drug-related death (post release) & $60,000.00$ & 30 \\
\hline \multicolumn{3}{|l|}{ Indirect security/criminal justice } \\
\hline Adjudication & 30.00 & 30,40 \\
\hline Added sentence day & 103.00 & 46 \\
\hline Arrest & 2199.68 & 47 \\
\hline Court appearance & 1100.78 & 47 \\
\hline
\end{tabular}


Table 4 Budgetary Impact Results

\begin{tabular}{|c|c|c|c|}
\hline & Standard of Care & PRB Introduction & Difference \\
\hline \multicolumn{4}{|l|}{ Patients in treatment $(\mathrm{n})$} \\
\hline Methadone & 150 & 105 & -45 \\
\hline Prolonged-release buprenorphine & 0 & 45 & +45 \\
\hline \multicolumn{4}{|l|}{ Annual costs $(t)$} \\
\hline \multicolumn{4}{|l|}{ Direct service cost } \\
\hline Medication cost & 29,484 & $|5|, 5 \mid 5$ & $|22,03|$ \\
\hline Dispensing system fee & 3600 & 2520 & -1080 \\
\hline \multicolumn{4}{|l|}{ Staff cost } \\
\hline Prison Officer & 94,098 & 65,869 & $-28,229$ \\
\hline Nurse & 49,566 & 36,820 & $-12,746$ \\
\hline Pharmacy technician & 51,779 & 37,838 & $-13,940$ \\
\hline Pharmacist & 37,617 & 30,647 & $-6,970$ \\
\hline Prescriber & 26,277 & 22,335 & -3941 \\
\hline Total direct service & $£ 292,420$ & $£ 347,544$ & $£ 55,124$ \\
\hline \multicolumn{4}{|l|}{ Indirect health-care costs } \\
\hline Diversion-related medication review & 13,260 & 9282 & -3978 \\
\hline Overdose (staff resource) & 30,420 & 25,857 & -4563 \\
\hline Naloxone & 1273 & 1082 & -191 \\
\hline Ambulance callout & 255 & 217 & -38 \\
\hline Drug-related death (in custody) & 2494 & 2120 & -374 \\
\hline Drug-related death (postrelease) & 48,930 & 41,591 & -7340 \\
\hline Total indirect health care & $£ 96,632$ & $£ 80,148$ & $-£ \mid 6,484$ \\
\hline \multicolumn{4}{|l|}{ Indirect security/criminal justice costs } \\
\hline Adjudication: drug-related violence & 1572 & $|43|$ & -142 \\
\hline Adjudication: diversion & 23,400 & 16,380 & -7020 \\
\hline Sentence extension: drug-related violence & 475 & 432 & -43 \\
\hline Arrests & 135,280 & 108,554 & $-26,726$ \\
\hline Court Appearances & 67,698 & 54,323 & $-13,374$ \\
\hline Total indirect security/criminal justice & $£ 228,425$ & $f 181,120$ & $-£ 47,305$ \\
\hline Total & $£ 617,477$ & $£ 608,813$ & $-£ 8665$ \\
\hline
\end{tabular}

(indirect health care) and $£ 228,425$ (indirect security or criminal justice). With PRB introduction predicted costs were $£ 347,544, £ 80,148$ and $£ 181,120$ respectively. Staff time of 3159 hours per year is available for other activities with the introduction of PRB, compared to standard of care (Appendix 1).

Sensitivity analysis assessed impact of medication dose, staff time needed to deliver treatment with methadone and prolonged-release buprenorphine, and adoption level of PRB on overall costs (Appendix 2). The analysis showed higher savings in prisons prescribing higher doses of methadone, or where staff time to deliver standard of care is greater, possibly due to prison geography or other security factors. A higher rate $(50 \%)$ of $\mathrm{PRB}$ adoption is associated with predicted cost reduction of $£ 14,441$ compared to standard of care. Additional analysis showed a cost saving of $£ 2624$ for a scenario in which half of the PRB cohort receive weekly medication instead of monthly.

\section{Discussion}

The introduction of PRB as an option for pharmacotherapy was associated with a predicted reduction in total costs for OUD care for a typical population requiring OUD treatment in a prison in England. The evaluation predicted a reduction in indirect health care costs and security or criminal justice costs by $17 \%$ and $21 \%$ respectively, offsetting increases in direct costs. Reductions in staff time of $27 \%$ were predicted.

PRB can address limitations to the current prison OUD care system: optimal dosing for a sufficient duration, daily attendance at prison health care for observed therapy, the 
risk of bullying and harassment of prisoners to divert medications, maintaining continuity of buprenorphine care $^{3,15}$ avoiding the need to change to methadone. ${ }^{3}$ PRB may also benefit prisoners on release providing continuing treatment depending on recent administration and potentially changing the well described risk of overdose on release. Access to PRB may be very important at times when moving prisoners or personnel around the prison is highly undesirable and presents a significant health risk. PRB is likely a key resource when infectious disease or COVID-19 outbreaks are present.

There are limitations to this work. This is a predictive analysis based on assumptions-studies following introduction of PRB should test these results.

For the purpose of this analysis a "typical" prison setting, in which provision of pharmacotherapy forms a major part of the daily routine, was used for calculation of costs. In practice, costs to deliver care in an individual prison vary depending on caseload, prison geography, and security category. In prisons in which treatment services prescribe greater amounts of sublingual buprenorphine, baseline costs are likely to be significantly higher, and cost reduction from the introduction of PRB greater. This analysis is based on introduction of the PRB product which, according to the approved summary of product characteristics, does not require initiation with transmucosal buprenorphine-containing product followed by minimum seven days dose adjustment. Resources (time and cost of product) are not allocated for an induction phase. It is assumed for this analysis, those electing for PRB have previous experience of buprenorphine therapy.

Benefits over a longer period at a population level should also be assessed. In this analysis, the assumed reduction in mortality rate on release is based on a conservative approach: there may be a larger reduction in deaths for those maintaining PRB therapy on release. There are also likely other benefits not accounted for in this analysis. These other benefits may include: reallocation of staff time to provide improved OUD care, effective pharmacotherapy and continuity of care may be associated with improved treatment retention or less frequent "on top" use of illicit drugs, reduced bullying, violence or offences related to illicit drug use and lower mortality from opioid overdose which is a risk for prisoners, especially on release.

\section{Conclusion}

PRB offers an opportunity to improve care for OUD in prisons and can directly address many of the limitations of treatment today while reducing overall resource needs. It is recommended that decision-makers consider the benefits to individuals and the prison environment in general which may be offered by PRB in the context of overall cost reduction.

\section{Abbreviations}

OUD, opioid use disorder; PRB, prolonged-release buprenorphine.

\section{Data Sharing Statement}

All data generated or analysed during this study are included in this published article.

\section{Ethics Approval and Consent to Participate}

This is a nonhuman study based on analytical estimation of the cost of care. Ethics approval is not required.

\section{Funding}

Camurus AB provided funds for the study. Camurus had no influence on the development, research or writing of the manuscript.

\section{Disclosure}

Dr Richard Littlewood reports grants from Camurus, during the conduct of the study. The authors report no other conflicts of interest in this work.

\section{References}

1. Dematteis M, Auriacombe M, D'Agnone O, et al. Recommendations for buprenorphine and methadone therapy in opioid use disorder: a European consensus. Expert Opin Pharmacother. 2017;00 (00):14656566.2017.1409722. doi:10.1080/14656566.2017.1409722

2. Lang K, Neil J, Wright J, Dell CA, Berenbaum S, El-Aneed A. Qualitative investigation of barriers to accessing care by people who inject drugs in Saskatoon, Canada: perspectives of service providers. Subst Abuse Treat Prev Policy. 2013;8:35. doi:10.1186/1747-597X8-35

3. HM Inspectorate of Prisons. Changing patterns of substance misuse in adult prisons and service responses. 2015.

4. World Health Organization. Regional Office for Europe. Preventing overdose deaths in the criminal-justice system. 2014.

5. Clinical Guidelines on Drug Misuse and Dependence Update 2017 Independent Expert Working Group. Drug Misuse and Dependence: UK Guidelines on Clinical Management. London: Global and Public Health/Population Health/Healthy Behaviours/25460; 2017.

6. Coid J, Carvell A, Kittler Z, Healey A, Henderson J Opiates, criminal behaviour, and methadone treatment. 2000.

7. Jewkes Y, Crewe B, Bennett J. Handbook on Prisons. 2nd ed. Oxford: Taylor \& Francis; 2016.

8. Cooper R, Labour MP, Lancashire W House of commons health and social care committee. Prison health. Twelfth Report of Session 2017-19. 2018;November. 
9. Northamptonshire Healthcare NHS Foundation Trust. MMPr027/ HMP controlled drug procedure for HMP bedford.; 2018.

10. RCGP Secure Environments Group. Safer prescribing in prisons. Guidance for clinicians. 2011.

11. Nielsen S, Degenhardt L, Larance B, Gowing L, Kehler C, Lintzeris N Opioid agonist treatment for pharmaceutical opioid dependent people (protocol). 2016. doi:10.1002/14651858.CD011117

12. Mattick R, Breen C, Kimber J, Davoli M. Methadone maintenance therapy versus no opioid replacement therapy for opioid dependence (Review). Cochrane Database Syst Rev. 2009;(3). doi:10.1002/ 14651858.CD002209.pub2.www.cochranelibrary.com

13. Stöver H, Michels II. Drug use and opioid substitution treatment for prisoners. Harm Reduct J. 2010;7:17. doi:10.1186/1477-7517-7-17

14. Bi-Mohammed Z, Wright N, Hearty P, King N, Gavin H. Prescription opioid abuse in prison settings: a systematic review of prevalence, practice and treatment responses. Drug Alcohol Depend. 2017;171:122-131. doi:10.1016/j.drugalcdep.2016.11.032

15. Webster R Service user views on Opioid Substitute Treatment in Prison and on Release.

16. Public Health England. Secure setting statistics from the National Drug Treatment Monitoring System (NDTMS). 2017.

17. Bukten A, Skurtveit S, Tverdal A, Strang J, Clausen T. High risk of overdose death following release from prison: variations in mortality during a 15-year observation period. Addiction. 2017;112 (8):1432-1439. doi:10.1111/add.13803

18. European Medicines Agency. Buvidal Buprenorphine, Summary of Opinion (Initial Authorisation). 2018.

19. National Institute for Health and Care Excellence. Evidence review. Opioid dependence: buprenorphine prolonged-release injection (Buvidal). 2019.

20. Lofwall MR, Walsh SL, Nunes EV, et al. Weekly and monthly subcutaneous buprenorphine depot formulations vs daily sublingual buprenorphine with naloxone for treatment of opioid use disorder a randomized clinical trial. JAMA Intern Med. 2018;178(6):764-773. doi:10.1001/jamainternmed.2018.1052

21. Frost M, Bailey GL, Lintzeris N, et al. Long-term safety of a weekly and monthly subcutaneous buprenorphine depot (CAM2038) in the treatment of adult outpatients with opioid use disorder. Addiction. 2019:add.14636. doi:10.1111/add.14636.

22. University of Vermont. Opioid epidemic linked to childhood emotional abuse, study shows Findings suggests new treatment approaches for opioid abusers. ScienceDaily. 2017. doi:10.1016/j.ad

23. Healthcare Improvement Scotland. SMC 2169 buprenorphine 8/16/ 24/32/64/96/128mg prolonged-release solution for injection (Buvidal ${ }^{\circledR}$ ). 2019;(August):1-13.

24. Vorspan F, Hjelmström P, Simon N, et al. What place for prolongedrelease buprenorphine depot-formulation Buvidal ${ }^{\circledR}$ in the treatment arsenal of opioid dependence? Insights from the French experience on buprenorphine. Expert Opin Drug Deliv. 2019;16(9):907-914. doi:10.1080/17425247.2019.1649252
25. National Institute for Health and Care Excellence. Evidence review opioid dependence: buprenorphine prolonged- release injection (Buvidal); 2019. https://www.nice.org.uk/advice/es19/evidence/evi dence-review-pdf-6666819661. Accessed August 5, 2020.

26. Dunlop A Depot buprenorphine for opioid dependence in prisons in NSW, Australia. Lisbon Addiction.

27. Prison Health Services Methadone at HMP The Mount. Available from: https://bulger.co.uk/prison/methadoneblog.htm. Accessed August 10, 2020.

28. Ministry of Justice. Population Bulletin: Monthly April 2019. 2019.

29. NICE. TA 114 Methadone and buprenorphine for the management of opioid dependence. 2007. doi:10.2165/11632820-000000000-00000

30. Expert communication. 2019.

31. Sordo L, Barrio G, Bravo MJ, et al. Mortality risk during and after opioid substitution treatment: systematic review and meta-analysis of cohort studies. BMJ. 2017;j1550. Doi:10.1136/bmj.j1550.

32. North East Ambulance Service NHS Foundation Trust. Freedom of Information Act 2000 - Information Request FOI.18.074. 2018.

33. Prisons \& Probation Ombudsman. Annual Report 2017 - 18. 2018.

34. Marsden J, Stillwell G, Jones H, et al. Does exposure to opioid substitution treatment in prison reduce the risk of death after release? Natl Prospect Obs Study Engl. 2017;112:1408-1418. doi:10.1111/add.13779

35. Ministry of Justice. Offender management statistics quarterly: adjudications. 2017.

36. O'Hagan A, Hardwick R. Behind bars: the truth about drugs in prisons. Forensic Res Criminol Int J. 2017;5(3):00158. doi:10.15406/frcij.2017.05.00158

37. Kopak AM, Dean LV, Proctor SL, Miller L, Ho NG. Effectiveness of the rehabilitation for addicted prisoners trust (RAPt) programme. $J$ Subst Use. 2015;20(4):254-261. doi:10.3109/14659891.2014.904938

38. NHS. NHS Electronic Drug Tariff. 2019.

39. Medilogic UK. Personal communication. 2018.

40. HM Prison \& Probation Service. 10336 - Band 4 - Supervising Officer.

41. Care UK. Staff Nurse vacancy.

42. Care UK. Pharmacy Technician vacancy.

43. Care UK. Pharmacist vacancy.

44. NHS. Consultant Psychiatrist (Prison Service).

45. Scott D. Saying NO to the mega prison. Justics Power Res. 2018;2 (1):204-221.

46. Ministry of Justice. Costs per Place and Costs per Prisoner by Individual Prison. 2018.

47. Kenworthy J, Yi Y, Wright A, Brown J, Maria Madrigal A, Dunlop WCN. Use of opioid substitution therapies in the treatment of opioid use disorder: results of a UK cost effectiveness modelling study. J Med Econ. 2017;20(7):740-748. doi:10.1080/13696998.2017.1325744
ClinicoEconomics and Outcomes Research

\section{Publish your work in this journal}

ClinicoEconomics and Outcomes Research is an international, peerreviewed open-access journal focusing on Health Technology Assessment, Pharmacoeconomics and Outcomes Research in the areas of diagnosis, medical devices, and clinical, surgical and pharmacological intervention. The economic impact of health policy and health systems organization also constitute important areas of coverage. The manuscript management system is completely online and includes a very quick and fair peer-review system, which is all easy to use. Visit http://www.dovepress.com/testimonials.php to read real quotes from published authors. 